Bulletin of the Seismological Society of America. Vol. 50, No. 1, pp. 81-85. January, 1960

\title{
NOTE ON THE VARIATIONAL AND HOMOGENEOUS LAYER APPROXI- MATIONS FOR THE COMPUTATION OF RAYLEIGH-WAVE DISPERSION
}

\author{
By Frank Press and Hitoshi Takeuchi
}

\begin{abstract}
An earlier study of upper mantle structure using a variational method is repeated using the homogeneous layer approximation programmed for an electronic digital computer to obtain dispersion curves. The dispersion curves computed by the two methods differ significantly but systematically so as to yield the same conclusion about the presence of the Gutenberg low-velocity zone in the upper mantle.
\end{abstract}

\section{INTRODUCTION}

THE IMPORTANCE of surface-wave dispersion as a means of deducing in fine detail the variation of elastic parameters with depth in the earth has focused attention on the problem of computing dispersion curves. Of particular interest is the case where elastic velocity and density vary arbitrarily with depth. Recently two methods have been used to compute theoretical dispersion curves in order to study mantle structure. Takeuchi, Press, and Kobayashi (1959, hereafter denoted as paper 1), used dispersion curves simply determined by a third-order variational method to demonstrate that mantle Rayleigh-wave dispersion required the existence of the Gutenberg low-velocity zone in the upper mantle. Dorman, Ewing, and Oliver (1960), in their elegant study of mantle structure, use the homogeneous layer approximation to determine dispersion curves. They have programmed on an electronic digital computer the matrix iteration method of Haskell (1953) so that dispersion curves for earth models consisting of a large number of flat-lying, homogeneous, isotropic layers could be expeditiously obtained.

It is the purpose of the present paper to check our conclusions reached with the variational method by repeating the calculation, using the homogeneous layer approximation. It will be seen that the theoretical dispersion curves computed by the two methods differ significantly but in a systematic way so as to yield the same conclusion about the existence of the low-velocity zone. Which of the two approximate methods is more accurate is a question now receiving our attention.

\section{Procedure}

The matrix iteration method of Haskell was programmed to yield period and group velocity for given phase velocity on the Seismological Laboratory's electronic digital computer, the Bendix G-15D. Up to 20 layers may be included in the calculation, keeping within the limits of the main memory of the computer. More layers can be included by using auxiliary magnetic tape memory.

The two velocity-depth functions described in paper 1 (see tables 1 and 2) were taken as representative of mantle structure with and without the low-velocity zone. The former was based on Gutenberg's work. The latter was based on the JeffreysBullen data for depths greater than $200 \mathrm{~km}$; it is modified for shallower depths to connect smoothly with the compressional and shear velocities of $8.2 \mathrm{~km} / \mathrm{sec}$. and

Manuscript received for publication July 22, 1959, with additions received September 22, 1959. 
TABLE 1

Gutgnberg Case

\begin{tabular}{|c|c|c|c|}
\hline Layer thickness & Compressional velocity & Shear velocity & Density \\
\hline $\mathrm{km} / \mathrm{sec}$ & $\mathrm{km} / \mathrm{sec}$ & $\mathrm{km} / \mathrm{sec}$. & $\mathrm{gm} / \mathrm{cc}$. \\
\hline $35 \ldots \ldots \ldots \ldots \ldots \ldots \ldots \ldots$ & 6.100 & 3.535 & 2.80 \\
\hline $65 . \ldots \ldots \ldots \ldots \ldots \ldots \ldots \ldots$ & 8.200 & 4.700 & 3.30 \\
\hline $50 \ldots \ldots \ldots \ldots \ldots \ldots \ldots$ & 8.000 & 4.400 & 3.38 \\
\hline $50 \ldots \ldots \ldots \ldots \ldots \ldots \ldots \ldots$ & 7.850 & 4.350 & 3.42 \\
\hline $100 \ldots \ldots \ldots \ldots \ldots \ldots \ldots$ & 8.050 & 4.400 & 3.47 \\
\hline $100 \ldots \ldots \ldots \ldots \ldots \ldots \ldots$ & 8.500 & 4.600 & 3.55 \\
\hline $100 \ldots \ldots \ldots \ldots \ldots \ldots$ & 9.000 & 4.950 & 3.63 \\
\hline $100 \ldots \ldots \ldots \ldots \ldots \ldots \ldots$ & 9.600 & 5.300 & 3.89 \\
\hline $100 \ldots \ldots \ldots \ldots \ldots \ldots$ & 10.100 & 5.600 & 4.13 \\
\hline $100 \ldots \ldots \ldots \ldots \ldots \ldots \ldots \ldots$ & 10.500 & 5.900 & 4.33 \\
\hline $100 \ldots \ldots \ldots \ldots \ldots \ldots \ldots \ldots$ & 10.900 & 6.150 & 4.49 \\
\hline $100 \ldots \ldots \ldots \ldots \ldots \ldots \ldots$ & 11.300 & 6.300 & 4.60 \\
\hline $200 \ldots \ldots \ldots \ldots \ldots \ldots$ & 11.400 & 6.350 & 4.68 \\
\hline 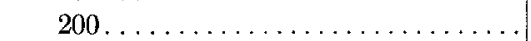 & 11.800 & 6.500 & 4.80 \\
\hline 200 . & 12.050 & 6.600 & 4.91 \\
\hline $200 \ldots \ldots$ & 12.300 & 6.750 & 5.03 \\
\hline $200 \ldots \ldots$ & 12.550 & 6.850 & 5.13 \\
\hline $200 \ldots \ldots \ldots \ldots \ldots \ldots \ldots$ & 12.800 & 6.950 & 5.24 \\
\hline $200 \ldots \ldots \ldots \ldots \ldots \ldots$ & 13.000 & 7.000 & 5.34 \\
\hline $9999999 \ldots \ldots \ldots \ldots \ldots \ldots \ldots \ldots$ & 13.500 & 7.200 & 5.54 \\
\hline
\end{tabular}

TABLE 2

Jefrrets-Bullen (Modified) CASe

\begin{tabular}{|c|c|c|c|}
\hline Layer thickness & Compressional velocity & Shear velocity & Density \\
\hline $\mathrm{km} / \mathrm{sec}$ & $\mathrm{km} / \mathrm{sec}$ & $\mathrm{km} / \mathrm{sec}$. & $\mathrm{gm} / \mathrm{cc}$ \\
\hline $35 .$. & 6.100 & 3.535 & 2.80 \\
\hline $265 .$. & 8.200 & 4.700 & 3.30 \\
\hline $100 \ldots$ & 8.580 & 4.760 & 3.55 \\
\hline 100. & 8.930 & 4.940 & 3.63 \\
\hline $100 \ldots$ & 9.660 & 5.320 & 3.89 \\
\hline $100 .$. & 10.240 & 5.660 & 4.13 \\
\hline $100 \ldots$ & 10.670 & 5.930 & 4.33 \\
\hline $100 \ldots$ & 11.010 & 6.130 & 4.49 \\
\hline $100 \ldots$ & 11.250 & 6.270 & 4.60 \\
\hline $200 \ldots \ldots$ & 11.430 & 6.360 & 4.68 \\
\hline $200 \ldots \ldots \ldots \ldots \ldots$ & 11.710 & 6.500 & 4.80 \\
\hline $200 \ldots \ldots \ldots \ldots \ldots$ & 11.990 & 6.620 & 4.91 \\
\hline $200 \ldots \ldots \ldots \ldots \ldots$ & 12.260 & 6.730 & 5.03 \\
\hline $200 \ldots \ldots \ldots \ldots \ldots$ & 12.530 & 6.830 & 5.13 \\
\hline $200 \ldots \ldots \ldots \ldots \ldots \ldots$ & 12.790 & 6.920 & 5.24 \\
\hline $200 \ldots \ldots \ldots \ldots \ldots$ & 13.030 & 7.020 & 5.34 \\
\hline $9999999 \ldots$ & 13.500 & 7.200 & 5.54 \\
\hline
\end{tabular}


TABLE 3

Results for Gutenberg Case

\begin{tabular}{c|c|c|c|c|c}
\hline$c / \beta_{1}$ & $K d_{1}$ & $T$ & $c$ & $U$ & $\begin{array}{c}\text { No. of } \\
\text { layers }\end{array}$ \\
\hline & & sec. & $\mathrm{km} / \mathrm{sec}$. & $\mathrm{km} / \mathrm{sec}$. & \\
1.590 & 0.0836 & 467.90 & 5.621 & 4.624 & 20 \\
1.500 & .1114 & 372.30 & 5.303 & 4.144 & 20 \\
1.430 & .1359 & 320.08 & 5.055 & 3.992 & 20 \\
1.360 & .1655 & 276.38 & 4.808 & 3.572 & 20 \\
1.290 & .2058 & 234.36 & 4.560 & 3.560 & 18 \\
1.210 & .2875 & 178.82 & 4.277 & 3.605 & 18 \\
1.170 & .3791 & 140.27 & 4.136 & 3.760 & 15 \\
1.150 & 0.4859 & 111.33 & 4.065 & 3.869 & 11 \\
\hline
\end{tabular}

a Number of layers listed in tables 1 or 2 used in the computation, counting from top of section.

TABLE 4

Results for Jeffreys-Bullen (Modified) Case

\begin{tabular}{c|c|c|c|c|c}
\hline \hline$c / \beta_{1}$ & $K d_{1}$ & $T$ & $c$ & $U$ & $\begin{array}{c}\text { No. of } \\
\text { layers }\end{array}$ \\
\hline & & sec. & $\mathrm{km} / \mathrm{sec}$. & $\mathrm{km} / \mathrm{sec}$. & \\
1.590 & 0.0867 & 451.26 & 5.621 & 4.678 & 17 \\
1.500 & .1165 & 356.04 & 5.303 & 4.103 & 17 \\
1.450 & .1355 & 316.52 & 5.126 & 3.970 & 17 \\
1.370 & .1736 & 261.57 & 4.843 & 3.776 & 17 \\
1.290 & .2344 & 205.73 & 4.560 & 3.799 & 17 \\
1.240 & .3088 & 162.48 & 4.383 & 3.898 & 12 \\
1.210 & .4027 & 127.69 & 4.277 & 3.969 & 12 \\
1.190 & 0.5411 & 96.61 & 4.207 & 4.022 & 12 \\
\hline
\end{tabular}

s Number of layers listed in tables 1 or 2 used in the computation, counting from top of section.

$4.7 \mathrm{~km} /$ sec. at the $M$ discontinuity which are more in keeping with recent results from explosions and rockbursts. The Gutenberg case was represented by up to 20 homogeneous layers, and up to 17 layers were used for the modified Jeffreys-Bullen case. For given phase velocity, period and group velocity were computed. Although for the purposes of this note only phase velocity is needed in graphical form, the complete tabular results are given in tables 3 and 4 . Presented are dimensionless phase velocity $c / \beta_{1}$, wave number $K d_{1}$, period $T$, phase velocity $c$, group velocity $U$.

\section{Resultis}

The results of paper 1 are reproduced in figure 1 together with the new results. The dashed curves are empirical phase-velocity curves concordant with observed mantle Rayleigh group velocity (Ewing and Press, 1956). They differ by a constant of integration introduced in deriving phase velocity from group velocity. Any theoretical phase-velocity curves concordant with the grid of empirical phase-velocity curves will yield a group velocity curve which is consistent with observed group 
velocities. The two continuous curves were derived by the variational method. The upper curve, which is discordant with the empirical grid, does not allow for the lowvelocity zone, whereas the better-fitting lower curve does. This was the basis of the conclusions reached in paper 1 . The circles and crosses represent the corresponding results for the homogeneous layer approximation. Again it is seen that the inclusion of the low-velocity zone gives a concordant solution (crosses), whereas the absence of this zone results in phase velocities which cut across the empirical grid. ${ }^{1}$

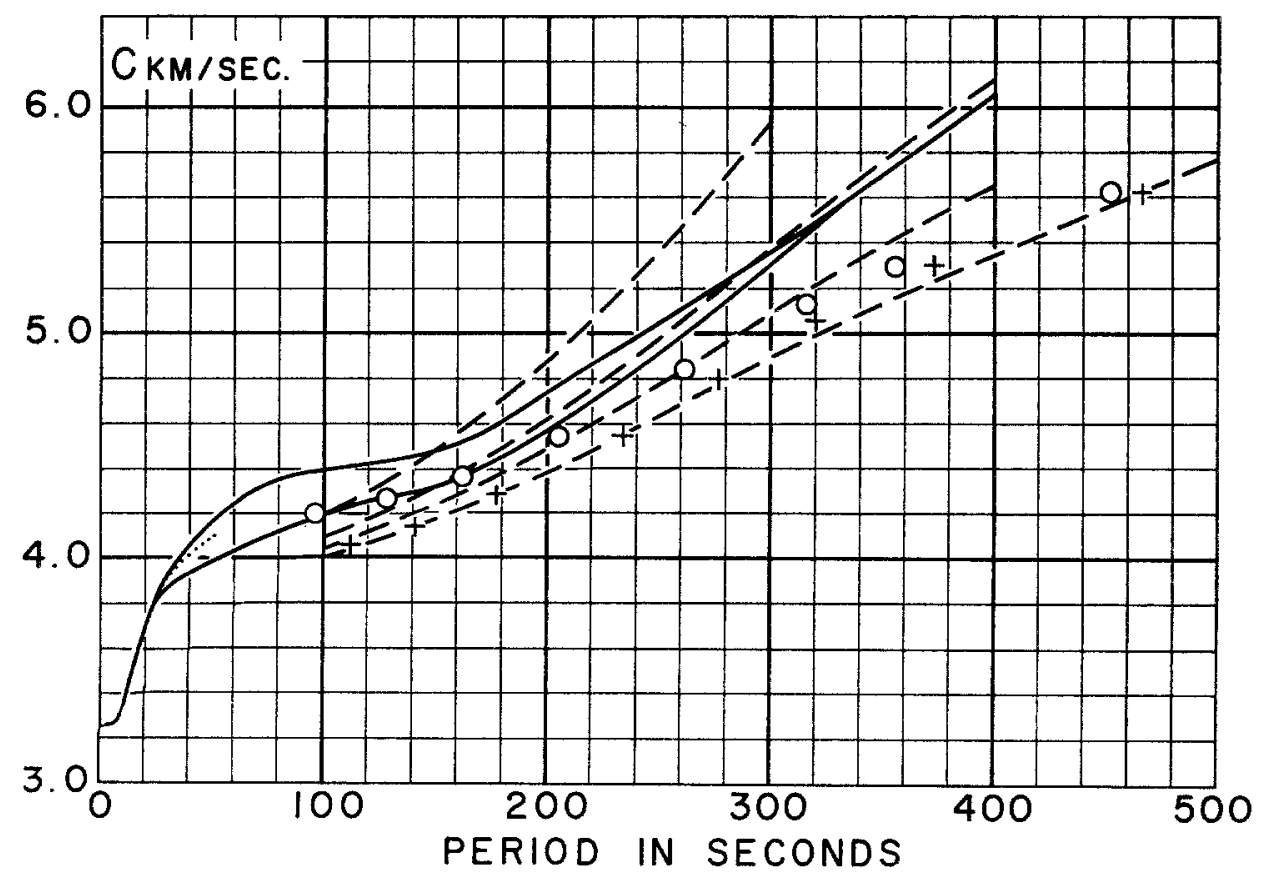

Fig. 1. Empirical phase-velocity data are shown by dashed lines. Solid curves show results of variational calculation without Gutenberg low-velocity zone (upper curve) and with low-velocity zone (lower eurve). Crosses show results of homogeneous-layers calculation including low-velocity zone, and circles give results excluding this zone. Note how crosses and lower solid curve are more concordant with empirical phase-velocity grid.

It is interesting that both methods of approximating dispersion curves agree in their conclusion about the need for the low-velocity zone. This follows because the phase-velocity curves derived by the two methods differ systematically in such a way as to correspond to the same group velocity.

\section{ACKNOWLEDGMENTS}

The authors are grateful to Drs. Dorman, Ewing, and Oliver for letting them see a prepublication copy of their manuscript. This work was supported by grants from the IGY interdisciplinary program and the Alfred P. Sloan Foundation.

\footnotetext{
${ }^{1}$ We have allowed for the slight differences between the Gutenberg and Jeffreys-Bullen solutions for depths greater than $400 \mathrm{~km}$. instead of taking an average solution for this region as was done in paper 1.
} 


\section{REFERENCES}

J. Dorman, M. Ewing, and J. Oliver

1960. "Study of Shear Velocity Distribution in the Upper Mantle by Mantle Rayleigh Waves," Bull. Seism. Soc. Am., 50: 87-115.

M. Ewing and F. Press

1956. "Rayleigh Wave Dispersion in the Period Range 10-500 Seconds," Trans. Am. Geophys. Union, 37: 213-215.

N. Haskell

1953. "Dispersion of Surface Waves on Multilayered Media," Bull. Seism. Soc. Am., 43: 17-34.

H. Takeuchi, F. Press, and N. Kobayashi

1959. "Rayleigh-Wave Evidence for the Low-Velocity Zone in the Mantle," Bull. Seism. Soc. Am., 49: 355-364.

F. P.

California Institute of Technology,

Pasadena, California.

(Division of the Geological Sciences, contribution no. 938.)

H. T.

Geophysical Institute,

TOKYO UNIVERSITY,

TOKYO, JAPAN. 